\title{
The Logic of Tact \\ How Decisions Happen in Situations of Crisis
}

Kornberger, Martin; Leixnering, Stephan; Meyer, Renate

Document Version

Accepted author manuscript

Published in:

Organization Studies

DOI:

$10.1177 / 0170840618814573$

Publication date:

2019

License

Unspecified

Citation for published version (APA):

Kornberger, M., Leixnering, S., \& Meyer, R. (2019). The Logic of Tact: How Decisions Happen in Situations of Crisis. Organization Studies, 40(2), 239-266. https://doi.org/10.1177/0170840618814573

Link to publication in CBS Research Portal

\section{General rights}

Copyright and moral rights for the publications made accessible in the public portal are retained by the authors and/or other copyright owners and it is a condition of accessing publications that users recognise and abide by the legal requirements associated with these rights.

Take down policy

If you believe that this document breaches copyright please contact us (research.lib@cbs.dk) providing details, and we will remove access to the work immediately and investigate your claim. 


\title{
The Logic of Tact: How Decisions Happen in Situations of Crisis
}

\author{
Martin Kornberger, Stephan Leixnering, Renate Meyer
}

Journal article (Accepted manuscript*)

\section{Please cite this article as:}

Kornberger, M., Leixnering, S., \& Meyer, R. (2019). The Logic of Tact: How Decisions Happen in Situations of Crisis. Organization Studies, 402), 239-266. https://doi.org/10.1177/0170840618814573

\section{DOl: https://doi.org/10.1177/0170840618814573}

Copyright (C) The Author(s) २०19. Reprinted by permission of SAGE Publications.

* This version of the article has been accepted for publication and undergone full peer review but has not been through the copyediting, typesetting, pagination and proofreading process, which may lead to differences between this version and the publisher's final version AKA Version of Record.

Uploaded to CBS Research Portal: August २०२० 
The logic of tact:

How decisions happen in situations of crisis

\author{
Martin Kornberger $1,2,4$ \\ Stephan Leixnering 2 \\ $\&$ \\ Renate Meyer ${ }^{2,3}$
}

${ }^{1}$ EM Lyon

${ }^{2}$ WU Vienna University of Economics and Business

${ }^{3}$ CBS Copenhagen Business School

${ }^{4}$ University of Edinburgh Business School

Contact:

kornberger@em-lyon.com 


\begin{abstract}
${ }^{\mathrm{i}}$
The mass-migration of refugees in the fall 2015 in Europe posed an immense humanitarian and logistical challenge: exhausted from their week-long journeys, refugees arrived in Vienna in need of care, shelter, food, medical aid, and onward transport. The refugee crisis was managed by an emerging polycentric and inter-sectoral collective of organizations. In this paper, we investigate how leaders of these organizations made decisions in concert with each other and hence sustained the capacity to act as collective. We ask: what was the logic of decision-making that orchestrated collective action during the crisis? In answering this question, we make the following contribution: departing from March's logics of consequences and appropriateness as well as Weick's work on sensemaking during crisis, we introduce an alternative logic that informed decision-making in our study: the logic of tact. With this concept we (a) offer a better understanding of how managers may make decisions under the condition of bounded rationality and the simultaneous transgression of their institutional identity in situations of crisis; and we (b) show that in decision-making under duress cognition is neither ahead of action, nor is action ahead of cognition; rather, tact explicates the rapid switching between cognition and action, orchestrating decision-making through their interplay.
\end{abstract}

Keywords: logic of tact, decision-making, sensemaking, collective action, capacity to act, crisis 


\section{INTRODUCTION}

From the beginning of September until December 2015, around 300,000 refugees arrived in Vienna, most of them from war-torn Syria, Iraq and Afghanistan. At the height of the crisis daily more than 6,000 refugees crossed the Austrian border from Hungary en route to a better life, which most of them hoped to find in Germany and Sweden. The vast majority arrived at one of the two busiest train stations, Hauptbahnhof and Westbabnhof. The mass migration represented an immense humanitarian and logistical challenge. Tens of thousands of refugees were in need of food, shelter, medical aid, transport, and care every day. In total, throughout the four months over 1.3 million overnight stays were counted in the 73 emergency shelters. ${ }^{1}$

What we were fascinated by (personally and professionally) was how an emerging inter-sectoral collective collaboratively managed the crisis. This polycentric collective consisted at its core of nine key actors, including the administration of the City of Vienna, the city's agency responsible for the coordination of social services (FSW), the local rescue service unit $(M A 70)$, the police, the military, Austrian Federal Railways (ÖBB), two major NGOs (Caritas and ASB), and the civic start-up Train of Hope. With "polycentricity" (Ostrom, 2010) we allude to the multiple decision centers that co-existed in the collective, including the SanStab as decision-making arena in Vienna's town hall and the two "hotspots" at Hauptbahnhof and Westbahnhof. The collective of actors itself was characterized by a multitude of values, structures, and motives. Whilst, for example, the military, whose rolling kitchens provided food, is an organization trained for emergency situations, Train of Hope (that had the operational command over the Hauptbahnhof) initially had no formal structure, let alone operating procedures or protocols. Crucially, no central authority coordinated the collective of actors. Hence, the collective had to orchestrate decisions and actions with each other.

Acting in concert, this collective showed a remarkable degree of effectiveness: none of the 300,000 refugees had to sleep without a roof over their heads and everyone received basic care; transport on to wished-for destinations was organized smoothly; and life in Vienna continued without major interruptions. The political objective of managing the crisis in a "humanitarian and orderly way", as one of our interviewees put it, was by and large accomplished. Given the effectiveness, we were puzzled by the question how, during the crisis, leaders of key organizations constituting the collective made decisions and hence sustained the collective's capacity to act in concert. In order to investigate our research question, we conducted interviews with senior decision-makers from the nine organizations.

Theoretically, our study invites engagement with two distinct bodies of literature: decision-making and its semantic sibling, sensemaking. Yet, neither the logic of appropriateness nor the logic of consequences

\footnotetext{
${ }^{1}$ Data from the City of Vienna refugee crisis fact sheet. See also the rapidly growing literature on the refugee crisis, e.g. Simsa (2017) or Oscarsson and Danielsson (2018).
} 
(March, 1982; 1994; 2006) could fully explain our findings. Equally, the concept of sensemaking with its emphasis on identity, retrospectiveness, and the primacy of action over thinking (Weick, 1979; 1988; 1995) allowed only a partial understanding of our case. Complementing Weick's sensemaking approach and March's dual decision logics, our search for theorization of our findings led us to an important thinker of decision-making in situations of crisis - the Prussian general and author of $O n W a r$, Carl von Clausewitz $(1832 / 2005)$. He used "tact" to describe how, in situations of high uncertainty and extreme pressures, decisions are made.

Elaborating on the logic of tact, our paper suggests the following contribution to organization theory. We supplement the two well-worn modes of decision-making that March defined as logics of appropriateness and consequences with the logic of tact. This logic is neither based on shared routines nor on calculative rationality; rather, tact explores how actors make decisions under the condition of bounded rationality and the simultaneous transgression of their institutional identities in a situation of crisis. In so doing, we open up a conversation between decision-making theory and the sensemaking literature. Sensemaking is a critique at rational decision-making models, arguing that "action is always just a tiny bit ahead of cognition, meaning that we act our way into belated understanding" (Weick, Sutcliffe \& Obstfeld, 2005: 419). In fact, sensemaking suggests a reverse sequencing of thought and action. We argue that this reversal (like its rational choice nemesis) is problematic and suggest the concept of tact as conceptual link that stresses the critical interplay of thought and action in decision-making under duress.

The paper proceeds as follows: in the next section, we present our notion of crisis, the two decisionmaking logics, and sensemaking. After a brief account of our methodological choices we report our findings. In the discussion, we elaborate on the logic of tact as alternative modus operandi during crisis and relate the logic of tact to decision-making and sensemaking. We conclude with a brief reflection of our argument for future research.

\section{THEORETICAL ORIENTATION}

\section{Crisis as moment of decision-making}

The phenomenon we studied was the refugee crisis unfolding in Vienna in 2015. But what kind of crisis did this represent? To be sure, in the public discourse (such as during the elections in Germany and Austria in 2017 or in international media²) the term "refugee crisis" has been and still is used. Our interviewees provided a more nuanced picture: some described the events as refugee crisis; but they also thought of it as administrative crisis or political crisis. Others did not think of it as crisis at all because the event had a long, albeit ignored genesis in the war and terror that was escalating in 2015 in Syria and elsewhere.

\footnotetext{
${ }^{2}$ See for instance reporting in the New York Times (https://www.nytimes.com/2015/10/16/world/europe/europerefugee-crisis-questions.html) or the Financial Times (https://www.ft.com/content/d41e28cc-8bcb-11e7-9084d0c17942ba93)
} 
In search for clarification, we turned to the crisis management literature (see for an overview James, Wooten \& Dushek, 2011). In this literature, crisis is commonly described as unanticipated, surprising, and ambiguous event posing a significant threat leaving only short decision time (Dutton, 1986; Hermann, 1963; James \& Wooten, 2010; Pearson \& Clair, 1998). Such low-probability, high-impact events include industrial crisis (such as Chernobyl or the Challenger disaster; see Vaughan, 1996; Weick, 1988), natural disasters (such as the Mann Gulch fire, Weick, 1993; or the 2010 Icelandic ash cloud, Boin, Rhinard \& Ekengren, 2014), or what Perrow (1984) described as "normal accidents". In these instances, an exogenous shock (until its occurrence dormant as risk, see van der Vegt, Essens, Wahlström \& George, 2015) triggers a set of responses such as the maritime rescue efforts after $9 / 11$ or the response to the Columbia Space Shuttle explosion in 2003 (Beck \& Plowman, 2014; Kendra \& Wachtendorf, 2006).

Building on Ricœur (1988; see for debate in the crisis management literature Morin, 1993; Roux-Dufort \& Lalonde, 2013), we suggest a complementary notion of crisis. In medicine, Ricœur posited, a crisis marks the turning point of an illness, leading to a positive or negative development. In science, a crisis is a disruption of established epistemic cultures (Fleck's "thought-styles" or Kuhn's "paradigms") and disorientation in regards to the production and evaluation of truth claims. In economics, crisis is part of autonomous cycles in which booms are followed inevitably by busts: growth, crisis, and recovery are the (supposedly) natural flow of creative destruction. Karl Marx straightened the arrow of history; but also in his analysis, the crisis marks the point of passage between modes of production. Ricœur's examples point towards the original meaning of the Greek word krisis, which derives from krinein - meaning to decide and to incise: the crisis is the moment of decision, a radical interruption of temporality resulting in a loss of orientation that forces a decision which divides the flow of events (sometimes history) into a before and after (Ronge, 2015; Thomä, Festl \& Grosser, 2015).

This has important implications for understanding the nature of crisis: with Ricœur, crisis is characterized by a form of "pathology" of history - a dysfunction in regards to the link between past experience and future expectation. Crisis marks a radical openness towards the future; it means

"not knowing any longer what my position within the universe is; not knowing any longer which stable hierarchy of values should guide my preferences; not being able any longer to differentiate between friend and foe." (Ricœur, 1988: 54; own translation).

The radical openness towards the future and the instability concerning the present refer to the origin of the word crisis, i.e., to decide. Crisis in Ricœur's sense is always a crisis of decision-making: a moment in which a decision must happen; yet, at the same time, guideposts for decision-making are no longer in place as "hierarchy of values" guiding preferences and the social sense of self and "friend and foe" (Ricœur) are not providing stable foundations. Therefore, the emotional response to crisis is not fear (such as fear from fire) but existential angst, which has no identifiable object that could offer a grip for a 
learnt response. ${ }^{3}$ In these circumstances, Ricœur argues, engagement is the sole means through which to search for guidance for decision-making.

\section{March's logics of consequences and appropriateness ...}

This focus on decision-making necessitates engagement with two bodies of literature: decision-making and sensemaking. Starting with the former, we use James March's investigation into "how decisions happen" (1978; 1982; 1994; 2006) as point of departure. March (1978: 591) argued that action "is presumed to follow either from explicit calculation of its consequences in terms of objectives, or from rules of behavior that have evolved through processes that are sensible but which obscure from present knowledge full information on the rational justification for any specific rule." In a later contribution March (1994) elaborated on this argument and differentiated between the logic of consequences and the logic of appropriateness. According to March, the logic of consequences represents the dominant framework to understand decision-making. March described it as rational choice paradigm which

"holds that action should be a product of mind and choice, not tradition, rule, routine, or revelation; that choice should be derived from carefully considered expectations of future consequences, not from the dictates of habit, custom, identity, intuition, or emotion; that insight into the dynamics of histories can be obtained from abstract models of them; and that levels of intelligence superior to those produced by other procedures can be achieved through model-based rationality." (March, 2006: 203).

The key feature is "the presence of calculated choice between alternatives" (Schulz, 2014: 1). Such choice is guided by abstract models. Models lead to decisions that are "based on an evaluation of alternatives in terms of their consequences for preferences" (March, 1994: 57). The logic of consequences is a way of coping with bounded rationality: framing, anchoring, heuristics, and other cognitive biases are understood as boundary conditions of the rational decision-making model - not its nemesis (March, 1978; 2006).

March contrasts this logic with the "logic of appropriateness by which actions are matched to situations by means of rules organized into identities" (1994: 57). Basically, the logic of appropriateness takes into consideration tradition, rule, routine as well as habit, custom, identity, intuition, and emotion - the concepts that the logic of consequences excludes from its rational analysis. March argues that the logic of appropriateness guides decision-makers through determining "what their identities are, what the situation is, and what action is appropriate for persons such as they are in the situation in which they find themselves" (1994: 68). This logic assumes that actors recognize a situation as familiar, categorize it based on past experiences, which in turn allows developing a reaction in response. In order to know what is appropriate, one needs to be socialized into a specific context: internalizing role expectations (identity) and being able to index the environment (March speaks of "categorization”; see 1994: 70) are key.

\footnotetext{
${ }^{3}$ We thank our editor Robin Holt for this Kierkegaardian distinction.
} 
Appropriateness relies on the decision-maker's ability to read "cues and prompts" that are provided in order to "evoke particular identities" (March, 1994: 72). The condition for such reading are shared repertoires and institutionalized roles that can only evolve over time as " $[\mathrm{r}] \mathrm{ules}$ of appropriateness are seen as carriers of lessons from experience" (March \& Olson, 2015: 486). As March and Olson (2015: 478; emphasis added) summarize:

"The logic of appropriateness is a perspective that sees human action as driven by rules of appropriate or exemplary behavior, organized into institutions. Rules are followed because they are seen as natural, rightful, expected, and legitimate. Actors seek to fulfill the obligations encapsulated in a role, an identity, a membership in a political community or group, and the ethos, practices and expectations of its institutions."

Danner-Schröder and Geiger's (2016; see also Bechky \& Okhuysen, 2011; Wolbers \& Boersma, 2013) ethnography of decision-making and action in a crisis response team provides an apt illustration of this logic. The authors show how the crisis response organization equipped its employees with scripts and routines that enabled effective disaster relief. In this example, decision-making is coordinated through a shared sense of what is appropriate - which is developed through intensive training sessions and joint disaster simulation exercises.

The logic of appropriateness differs from the logic of consequences as it is based in culturally anchored, socially legitimate, and institutionally sanctioned identities that offer scripts for decision-making. Whereas the logic of appropriateness is habitual, the logic of consequences is deliberate; the former is "guided by imprints of prior action and the other driven by considerations of future alternatives" (Schulz, 2014: 5). Therefore, the two logics have a tendency to follow different temporal trajectories: the logic of appropriateness is anchored in the past whilst the logic of consequences is future-oriented. Critically, one may add that the two logics are not in exact equilibrium: the logic of appropriateness represents a somehow broader concept that leaves room for several forms of appropriateness (in plural). Indeed, one could stretch this argument as far as claiming that the logic of consequences represents but one specific case of what a profession (economists with a shared identity, etc.) deem to be most appropriate.

In sum, it has been claimed that March's two logics are "fundamental components of all meaningful action. Action without either logic is random and appears senseless (without "rhyme or reason"), while action shaped by the logics takes on direction and meaning" (Schulz, 2014: 2). Indeed, literatures across different domains including public administration (Entwistle, 2011; Goldmann, 2005), accounting (MacDonald \& Richardson, 2004), neo-institutionalism (Ocasio, 1999; Scott, 1995; Wicks, 2002), identity theory (Wilhelm \& Bort, 2013), narrative analysis (Abolafia, 2010), studies of conflict (McCarter, Budescu \& Scheffran, 2011) and power (Kopelman, Hardin, Myers \& Tost, 2016; Wagnsson, 2010) have utilized 
March's binary code of consequentialism and appropriateness, focusing either on the empirical illumination of one or the other or investigating the sequencing, convergence or clashing of them.

\section{... and Weick's sensemaking during crisis}

The second body of work that necessitates engagement is the seminal work of Karl Weick (1979; 1995; 1996; Weick et al., 2005) and especially his elaboration on sensemaking in situations of crisis (Weick, 1988; 1993; 2010; Gephart, 1984; 2007; for a policy perspective see Boin, Ekengren \& Rhinard, 2014). Weick's work on sensemaking in crisis situations represents a critique of decision-making. The critique follows from Weick's stance that it is interpretation, not choice, that is key (Weick, 1979). Consequently, only rarely does Weick engage with decision-making, and when he does so, he argues that action precedes decision-making, the latter being a rationalization of the former. For instance, Weick et al. (2005: 409-410, quoting Snook, 2001) use a friendly-fire incident to illustrate their stance: None of the actors involved in the tragic incident "decided" to shoot, and in this sense no one made the "wrong" decision. Rather, looking at "powerful contextual features" and "potent situation factors that influence action" allows for a reframing "from decision-making to sensemaking". Similarly, in his analysis of the Mann Gulch disaster, Weick (1993: 635) suggests a "shift from decision making to meaning" through studying sensemaking. The problem is that the

"world of decision making is about strategic rationality. It is built from clear questions and clear answers that attempt to remove ignorance [...]. The world of sensemaking is different.

Sensemaking is about contextual rationality. It is built out of vague questions, muddy answers, and negotiated agreements that attempt to reduce confusion" (Weick, 1993: 636).

For Weick, decision-making theory follows a rational choice program that does not allow capturing contextual rationality. There are several specific points of critique that Weick brings into play. First, sensemaking articulates a critique at rational consequentialist decision-making that suggests the primacy of thinking over acting. People "think by acting", so Weick (1988: 305), suggesting that action is a way of understanding and instigating decision-making. Second, sensemaking emphasizes that action is not merely “execution" but reflexive: it includes the senses, suggesting an understanding of decision-making as embodied process, something quite often ignored in studies of abstract cognition and rationality (Cunliffe \& Coupland, 2012; Stigliani \& Ravasi, 2012). Third, while rational choice-inspired decision-making theory sees its locus of analysis in the individual's mind, sensemaking is a collective and distributed process that is based on shared identities. ${ }^{4}$ For instance, in a notable study of waterborne evacuation of lower Manhattan in the wake of the 9/11 terror attack, Kendra and Wachtendorf (2006) show how individual boat owners and operators acted as collective without central coordinating management function; rather, the authors posit that making sense of identity cues facilitated collective action. For instance, a tugboat operator, a

\footnotetext{
${ }^{4}$ We are grateful that one of our reviewers argued that the sensemaking literature is divided on this point: while some scholars understand sensemaking as intersubjective process, others define it as individual accomplishment (see Maitlis \& Christianson, 2014). Whilst this debate is not the focus of our paper, we tend to agree with the first view.
} 
yacht owner, and a waterfront worker had, based on their shared sensemaking of each other's occupationspecific identities and skills, a sense of what the other would do next, which enabled collaboration. Of course, this reading of sensemaking echoes the logic of appropriateness that also understands coordination as outcome of shared repertoires, routines and rituals. Sensemaking's focus on action preceding decision (rather than rational choice's assumption that thought precedes action), its emphasis on embodiment and its attention to distributed collective action provide an important corrective to the consequentialist decision-making literature. Equipped with a Ricœurian sensibility towards crisis, Weick's sensemaking, and March's logics of decision-making, we will now turn to our data and method of inquiry.

\section{DATA AND METHOD}

\section{Context and key actors}

As the immediate refugee crisis came to a close in January 2016, we launched our research project. We started with a reconstruction of the timeline and sequence of major events based on a media analysis ${ }^{5}$ (see figure 1).

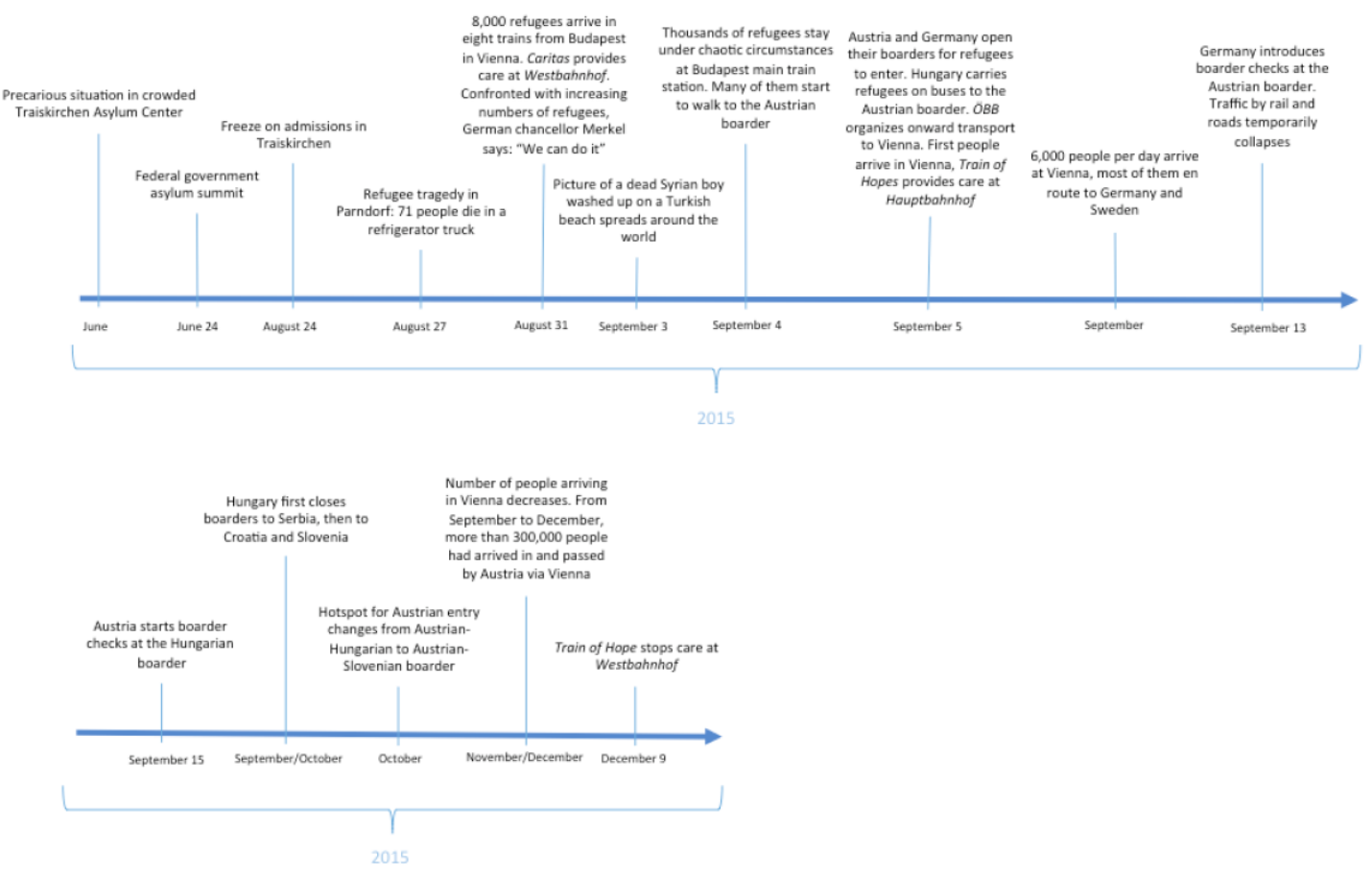

Figure 1: Timeline of the refugee crisis autumn 2015

The media analysis also provided us with initial information about the collective of actors that managed the crisis. The specificities of this collective are central for our case. Most importantly, there was no central authority in charge of coordination; Austria's federal government, which would have been the expected actor to take on this coordinating role, remained silent. In fact, media commentators argued that

\footnotetext{
${ }^{5}$ Using Factiva database, we identified 218 relevant newspaper articles, published by the Austrian liberal quality newspaper Der Standard in the period of January 2014 to December 2015.
} 
national authorities "failed", had "lost control", and were paralyzed. ${ }^{6}$ This left what one of our interviewees (M) described as "legal vacuum" (rechtsfreier Raum) - a vacuum that was filled mainly by the following nine key actors: the administration of the City of Vienna (government and chief executive office); Vienna's agency responsible for the coordination of social services (Fonds Soziales Wien - FSW, whose executive director was appointed "refugee crisis coordinator" by the city council); Vienna's medical rescue services unit (Magistratsabteilung $70-M A 70$ ); the Vienna Police Directorate (reporting to the Federal Ministry of Internal Affairs); the Vienna Military Command (reporting to the Federal Ministry of Defense); Austrian Federal Railways (Österreichische Bundesbabnen - ÖBB, an independent state-owned enterprise); two established NGOs (Caritas and Arbeiter-Samariter-Bund-ASB); as well as a grass-root civic movement (Train of Hope). For our study of decision-making two aspects are central: First, the collective of actors was highly diverse, including a leftist civil-society start-up (Train of Hope), the city administration as veritable bureaucracy, the $O B B B$ as corporate actor, police and military as (federal) hierarchical commandand-control bodies and two NGOs with ideologically rather opposite orientations. This collective had no prior experience of working with each other when they faced the crisis in autumn 2015. Second, decisionmaking throughout the crisis was polycentric and occurred in three main arenas: SanStab of the City of Vienna, a committee that was led by $M A 70$. The other hotspots were located at the two train stations: at Hauptbahnhof, the civil-society platform Train of Hope ran operations, whilst Caritas coordinated Westbahnhof. It is particularly noteworthy that Train of Hope did not exist prior to the crisis; nonetheless, within a few days, it established its lead at Vienna's main train station (Kornberger et al., , forthcoming). This polycentric collective collaborated to organize care, shelter, food, medical aid, and onward transport. In managing the crisis, they faced the challenge that in order to arrive at orchestrated action at the collective level, individual decision makers could not rely on established roles of and appropriate relations between organizations. What hence sparked our curiosity was how they nevertheless arrived at decisions that sustained collective action in the midst of the crisis. As we will argue, tact served as "bridging framework" that allowed orientation towards each other and in so doing sustained the collective's capacity to act. ${ }^{7}$

\section{Data collection}

The main source of data were semi-structured interviews. We approached the nine key organizations and invited their senior decision-makers in charge during the crisis for interviews with the aim to understand how decision-making had happened. We were interested in the managers' experiences, hence we focused on "the means by which organization members go about constructing and understanding their experience", as Gioia, Corley \& Hamilton (2013: 16) suggested. In our semi-structured interviews, we asked our interviewees about their experiences of and reflections on the management of the crisis, putting special emphasis on discussing with them how they made decisions and how their decision-making related to the mobilization of collective action. We prompted them to think how they navigated the pluralistic

\footnotetext{
${ }^{6}$ In addition to our media analysis see the well-respected German weekly Die Zeit (March 9, 2016) and the Austrian conservative quality newspaper Die Presse (August 20, 2016), which, in retrospect, spoke of "state failure" and "state authority failure" (Staatsversagen and Versagen von Autortität); so did the German newspaper Die Welt (November 9, 2015).

${ }^{7}$ We thank one of our reviewers for this formulation of tact as "bridging framework".
} 
landscape of different actors, and how situations of high uncertainty involving an alliance of actors with little or no shared past could be managed.

We interviewed 22 individuals, including top-officials and executives as well as leading activists. ${ }^{8}$ Building on our personal networks, and perhaps aided by the positive public perception of the management of the crisis, no interview request was denied. Acknowledging the highly charged political nature of information that interviewees shared with us, we guaranteed full anonymity. Given the relative ease to identify our interview partners, we replaced interviewees' names with letters and de-gendered them throughout the text. We were allowed to record all but two interviews. In these two, detailed notes were taken. The interviews lasted on average 75 minutes. In most cases, two of the authors conducted the interviews jointly; in our first interview, all three authors participated; and in six cases, one author led the interviews. This shared data collection allowed the researchers to frequently discuss emerging insights, ensuring an open and reflexive inquiry. For most of our interviewees, our conversation offered a welcome opportunity to reflect on the extraordinarily hectic months. To our surprise, despite the interviewed decision-makers coming from different organizations, they used similar vocabularies to describe decision-making. Perhaps this is less surprising as we were not so much interested in how they managed their own organizations internally, but how they acted in concert as they knew that the crisis could only be managed collectively.

\section{Data analysis}

Our analysis was guided by hermeneutic text analysis (see, e.g., Lueger, Sandner, Meyer \&

Hammerschmid, 2005) and structured by an inductive analytical process (as outlined, for example, by Gioa et al., 2013). The following steps outline how we translated our data into the narrative we present in the findings. In a first step, we captured those instances and episodes in which our interviewees referred to decision-making during the crisis, explicitly or implicitly. This included passages in which they explained how they arrived at decisions (for instance, $\mathrm{C}$ reflected on being out of the office as precondition for sustaining the capacity to make decisions); how they made decisions (for instance, $\mathrm{E}$ spoke about the speed of decision-making and the resulting pressures); or how decisions happened (for instance, $\mathrm{M}$ told about how the decision to establish a child care facility happened). During this phase, we listened as closely as possible to our informants" "voices" as we "would have missed a key aspect of their sensemaking by imposing our preordained understandings on their experience." (Gioa et al., 2013: 17; italics in original).

Equipped with utterances relating to decision-making, the second step of our interpretative work consisted of paraphrasing and categorizing various aspects of decision-making. In a process of repeat and

\footnotetext{
${ }^{8}$ Among these were top-officials such as a city counsellor, the $\mathrm{COO}$, and the refugee crisis coordinator of the City of Vienna, police and military officers, top-executives from ÖBB, Caritas, and ASB. Eight of our interviewees were activist-managers of Train of Hope, all of them in leadership roles at the beginning and/or throughout the crisis. The reason for the higher number is that we had difficulties identifying decision-makers with the civil-society start-up that was organized, at least initially, as flat and open network; we ensured in our analysis that we did not overrepresent Train of Hope and that our narrative is not skewed towards them.
} 
lengthy discussion amongst the authors and re-immersion in the data we looked for recurrent themes within and across the interviews in order to discover patterns and deeper structures. In our analysis, we realized that both, the logic of consequences and the logic of appropriateness were problematic ("incalculability \& uncontrollability" and "lack of shared routines within and shared identity across the collective of actors"). Instead, we arrived at two more cognitively inflected aspects of decision-making ("sensing as experiential activity" and "sensing as collective \& distributed accomplishment") and two action-oriented aspects (focusing on "agility through emergence \& decentralization" and "directionality through hierarchization \& countenance").

In our third and final interpretative step we created a dialogue between extant research and our own data and its interpretation (Alvesson \& Kärreman, 2007). March's logics of appropriateness and consequences and Weick's sensemaking provided the points of departure. ${ }^{9}$ Puzzled by how our interviewees reflected on their decision-making, Clausewitz's concept of tact (1832/2005) offered itself as alternative scheme to theorize our findings, and translate them into a conceptual contribution. Figure 2 summarizes the analytical work leading from interview data to findings.

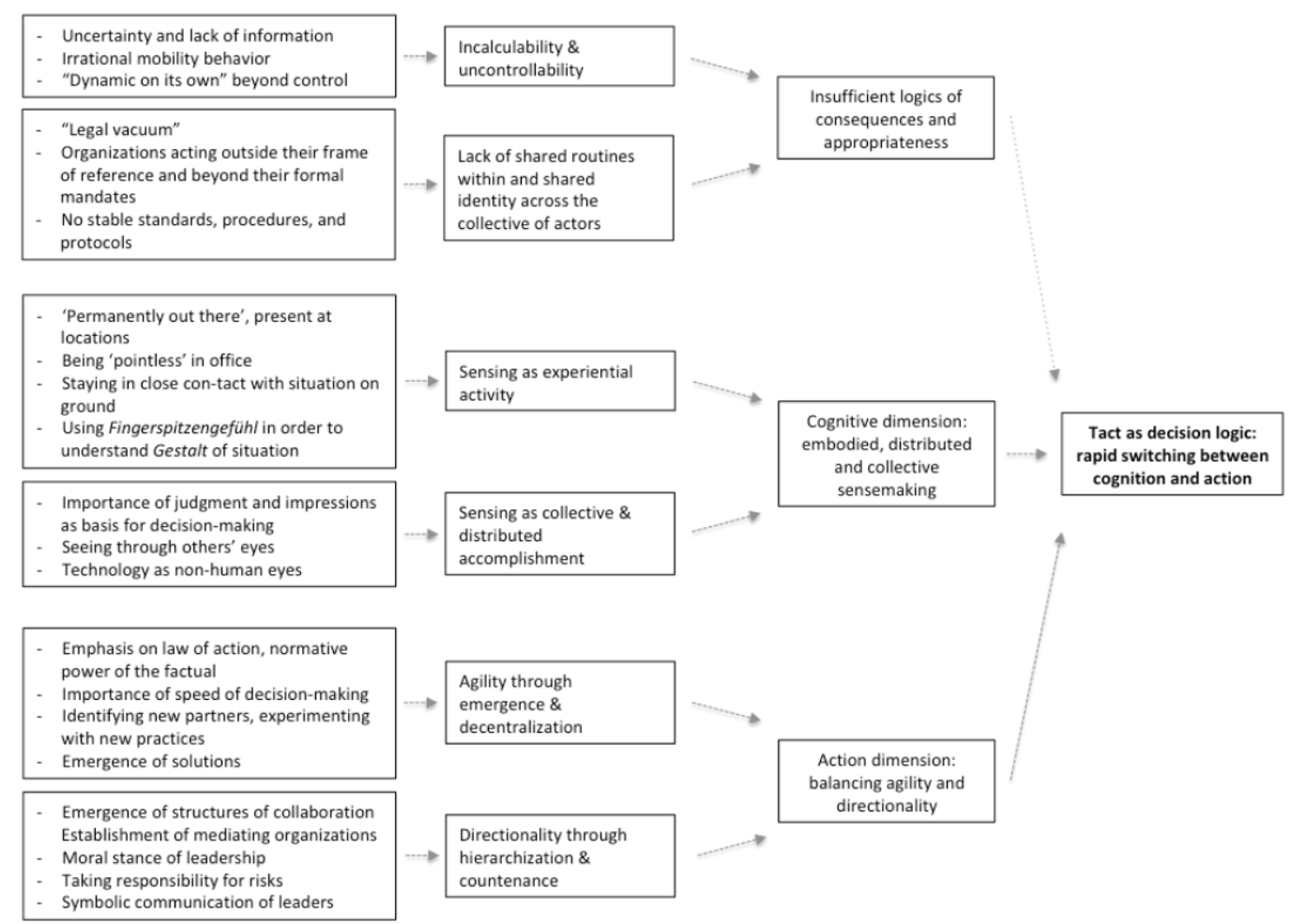

Figure 2: Data structure

\section{Caveat}

Our methodological choices necessitate acknowledging some limitations of our study. Our focus was on senior decision-makers. Hence, our paper represents their voices and does not include those of thousands

\footnotetext{
${ }^{9}$ Weick's sensemaking became more central during the review process; we would like to thank our reviewers for this
} extension of our theoretical horizon. 
of employees, volunteers, and citizens that collectively did what was needed to care for the refugees; nor does our paper give voice to the refugees themselves. Given the nature of our data collection, the valueadd of our narrative is not the quantity (breadth) of data but the quality (depth) of our conversations, providing "thick descriptions" (Ryle, 1971) of how key decisions makers thought and acted under duress. Hence, our study is illustrative, designed to instigate curiosity, not closure. Last but not least, the orderly "context of presentation" our paper adheres to differs from the messy "context of discovery" (Mills, 1959), in which interviews and insights echoed and amplified each other.

\section{FINDINGS}

\section{Beyond the logic of consequences and logic of appropriateness}

Our analysis revealed that neither the logic of consequences nor the logic of appropriateness could fully account for what we observed: Our interviewees stressed repeatedly that uncertainty and lack of information was one of the major impediments for decision-making during the crisis. For instance, on 31 August, three trains with several hundred refugees were expected; by the end of the day, eight crowded trains with 8,000 refugees had arrived (M). Early September, ÖBB estimated that there were about a total of 20,000 refugees in Hungary. Four months later 300,000 had crossed the border (I). On a day-to-day basis, it was often not clear whether 500 or 5,000 refugees would arrive (B). Not only tasks but also framework conditions (Rahmenbedingungen) changed daily (M). This caused massive challenges in regards to organizing care, shelter, food, and onward transport. The uncertainty was extremely taxing for volunteers who would either be overworked or wait for hours for refugees, which both was demotivating (E; F). Additionally, the "mobility behavior" of refugees was perceived as "irrational" (I), defying analysis and prediction. The railway managers we interviewed $(\mathrm{I} ; \mathrm{J})$ told that once the masses were in motion, "they could not be stopped"; and other interviewees (M; O) confirmed that "coordination of streams" turned out to be extremely challenging. For instance, late in the evenings, when the last train had left, refugees would not leave the platforms for temporary accommodation. They were scared that buses would bring them to a detention facility. On their flight, they learned to mistrust officials. As one interviewee (I) put it, refugees "could not be directed"; it was not a decision to let them into the country or occupy a train station as they simply forced their way ahead. So ÖBB's strategy was to keep masses moving in orderly manners (I) - but there was a strong sense that masses could not be stopped. A senior police officer (M) concluded that the situation had taken on a "dynamic on its own" (Eigendynamik) that could not be controlled. Reflecting on the crisis, our interviewees clearly acknowledged the limits of rational decisionmaking. The lack of information and the dynamics of the situation made decision-making based on the logic of consequences an impossible task.

Our analysis also made clear that the logic of appropriateness was not a sufficient guide to orchestrate decision-making. First, most of the organizations that took responsibility acted outside their usual frame of reference, which implied that they could not rely on a sense of what was appropriate and what not. This unusual situation was a result of the federal government taking a passive stance (C; E). Hence the 
crisis unfolded in what a senior police officer described as "legal vacuum" (M). Consequently, when the first refugees arrived, organizations managing the crisis quickly found themselves acting beyond their formal mandates. For instance, a senior member of the city administration stated that during the crisis his/her organization acted constantly "outside its area of jurisdiction and competence" (C). This was problematic as in legalistic administrative traditions bureaucracies are supposed to act only based on laws and rules. The seemingly innocent phrase of offering "unbureaucratic help" (A; E) glosses over a deeply problematic issue: how can a bureaucracy make legitimate decisions "unbureaucratically"? It certainly pushed them beyond their sense of appropriateness, as our interviewees reflected: suspending bureaucratic rules (from legal working hours for employees to the Dublin agreement ${ }^{10}$ ) in the name of "humanity" meant at least bending those rules that appropriate administrative action is based upon. Equally, nongovernmental actors widely took over responsibilities from the state. Train of Hope, initially a handful of grass-root activists had the operational command over the Hauptbahnhof. Asking Caritas who provided them with the mandate to take control over Westbahnhof, one of its leaders answered: "We knew we should be there; after we started working there we got the mandate" (A). As one of our interviewees (C) stressed, the crisis was all about taking enormous risks when making decisions. In this challenging situation where identities and well-worn roles were questioned, the logic of appropriateness - based on established rules, routines, and identity - could not guide individual organizations' decision-making sufficiently.

A second reason why the logic of appropriateness could not inform decision-making was that the multitude of actors that managed the crisis was not equipped with established identities, let alone a shared past, that could provide a script for how to make decisions collectively. For sure, emergency response organizations such as the City of Vienna's $M A 70$ and the police could rely on a logic of appropriateness to coordinate their decision-making as they shared regular trainings and past experience (see Wolbers \& Boersma, 2013). For instance, the EURO 2008 soccer championship that took place in Vienna was mentioned as catalyst to develop shared protocols and standards $(\mathrm{O})$. But emergency response units were only a part of the collective. For instance, Train of Hope had no culturally anchored scripts that would provide guidance for decision-making. That is not to say that they did not have internally a sense of what was appropriate: indeed, we found a strong sense of identity and cohesion within the civic start-up; but there was no shared sense of appropriateness between them and other actors within the collective. For instance, a senior police commander stated that Train of Hope was clearly a major force to be reckoned with, albeit for him/her they remained "elusive" $(\mathrm{O})$. Hence, there were logics of appropriateness within the different acting organizations but no overarching logic that could have guided collective decisionmaking. On the contrary, we observed friction between different actors: for instance, Train of Hope was deeply suspicious about the established NGOs as they saw them as "businesses" that were concerned with using the refugee crisis to profile themselves in the media $(\mathrm{H} ; \mathrm{V})$; and the other organizations were

\footnotetext{
10 The Dublin Regulation (Regulation No. 604/2013) is part of the EU law that determines member states' responsibilities for the examination of asylum applications.
} 
suspicious of Train of Hope and its (lack of) standards, procedures and protocols. In short, appropriateness itself was a contested term, not a coordinating idea.

Hence, looking at our data, we found the logics of consequences and appropriateness both insufficient guides to decision-making: uncertainty, lack of information, extreme time pressure, and unpredictability made calculation of consequences futile. Individual organizations transcended their mandates and competences, and with them what they deemed appropriate internally; and the collective of actors with differing or unknown logics of what they deemed appropriate made it difficult to rely on appropriateness to coordinate decisions between them.

\section{Picturing reality during crisis: embodied, distributed and collective sensemaking}

Our interviewees stressed the utmost importance of developing a picture of the situation in the midst of the crisis. There was no time for data gathering, detailed analysis, and lengthy reporting - yet, as a senior manager from $O ̈ B B$ said: during the crisis "without a situation picture (Lagebild) even the best manager is lost" (I). How did our interviewees arrive at such picture? How did they make sense of the unfolding situation?

\section{Sensing as experiential activity: "permanently out there"}

The situation picture was accomplished through a bodily sensing of the situation in order to arrive at an understanding of its Gestalt. Indeed, it was surprising how the decision-makers spoke at length about their physical presence at the various sites. In fact, one of the most striking - and constant - answers we received when we asked how decision-making had changed during the crisis was that their locus of work had shifted. Rather than being in their offices, they were out at the hot spots, spending time at the train stations, emergency shelters, or in ad hoc on-site meetings. For instance, one interviewee explained that it was necessary to be "permanently out there, present at the location" (E). This physical presence allowed staying in "contact with the basis" and getting a sense for how things unfolded (D). S/ he continued that albeit one could gain an understanding from conversations in meetings, being present at site changed the picture of the crisis fundamentally. Another senior manager told us that s/he started every day with a trip to the two train stations (C). This was important in order to gain "an intuitive sense", s/he argued, and reflected further:

"During the crisis I figured out relatively quickly that I am pretty pointless (sinnlos) here in this office [laughingly gesturing towards the walls of his/her office where the interview takes place]. $[\ldots]$. For days I was not in my office; instead I was 16 hours on the road." (C)

Being present at the hotspots meant being in touch with the unfolding events; interviewees referred to their Fingerspitzengefübl - "feeling in the tips of one's fingers" - that was pivotal to handle delicate, complex situations. For instance, a senior decision-maker of Train of Hope $(T)$ reflected on how difficult it was to 
manage the 300 to 400 volunteer translators s/he was in charge of. Many translators had a migration background themselves, some even being refugees from the Iraq war in 2003. These volunteers reacted very emotionally towards the arriving refugees, and sometimes quite hostile towards each other. Yet translation was a crucial and sensitive issue, especially in medical situations (e.g., when a woman had to be brought to hospital and was treated by a male doctor). Our interviewee remembered how s/he had to slowly "feel my way" (berantasten, $\mathrm{T}$ ) towards "creating a team spirit", how s/he did this by walking around every day, talking to everyone and just "being out there" (T). S/he and our other interviewees kept their finger(tip)s on the pulse to sense the unknown situation. Fingerspitzengefübl led to contextual awareness and a situational picture that was needed to inform decision-making in the midst of the fog of crisis.

This sensing of the situation is not the same as a rational, abstract analysis of the situation nor is it a learned enactment of protocols or scripts based on recognition of the situation. Rather, our interviewees stressed the importance of immersing themselves in the situation and developing a sense of what was going on; they were indeed "engaged" in the crisis as Ricœur (1988) suggested, they stayed literally in touch with what happened. The important analytical point that follows: managerial decision-making was not based on "summary numerical representations of reality" (March, 1994: 15). Of course, reports were filed, analyses were prepared, accounts were kept; but these activities were described as "back office functions" (E). In the situation of crisis, the modus operandi of decision-makers changed: our interviewees put emphasis on the bodily sensing of the unfolding situation - requiring "feeling out" of the Gestalt of the crisis and its specific challenges.

\section{Sensing as collective and distributed accomplishment}

The situation picture also enrolled other eyes (and more generally: senses) in the task of creating a continuous update: sensemaking was not only embodied as outlined above but also a distributed and collective accomplishment. One way was to rely on perceptions by others that were closer to the action. Our interviewees emphasized the value of qualitative, subjective judgments. For instance, a senior ÖBB manager $(J)$ sent staff to Hungary to observe what was happening there and feed it back. As the crisis unfolded in the early September, s/he even asked staff who lived near the train stations en route to look out the windows of their homes in order to get an impression of how full trains were.

Non-human eyes complemented the distributed sensemaking. For instance, the ÖBB manager used hundreds of cameras that monitor train stations to get a live-feed of numbers. $S /$ he and his/her team looked at the videos and based on the density of the crowd they estimated how many people were out there. This was crucial for crowd management: it could have been disastrous if a train arrived at an already packed platform with hundreds of refugees waiting for a departing train. Since the incoming reports about numbers of refugees were unreliable - one interviewee (I) recollected that they could vary from 1,000 to 3,000 - the cameras were "eyes" that provided a sense of what was going on. As this senior ÖBB manager 
said, it was not about accurate body counts but shared "impressions" providing "a feeling of what is possible which alone is necessary in the situation to make a decision" (I).

It was not "seeing like a state" (Scott, 1998) but sensing through a collective that provided the information for the ever-changing situation picture. Having multiple, distributed "sensors" (eyes, fingertips) out there to collect information, and being in the midst of the action to "feel out the situation" allowed our interviewees to search, see and sense the environment to arrive at an actionable picture of the situation. Their sensemaking was first and foremost about fast orientation, about informed guesses: a form of distributed cognition that scans environments swiftly in order to delineate possibilities for action and search for alternatives. As one senior decision-maker from the city summarized, it was this "balancing act between action on site and strategic oversight" that enabled "truly effective leadership" (C).

\section{Action in crisis: balancing agility and directionality}

Sensemaking is argued to be interpretative, concerned with understanding and hence retrospect (Weick, 1995). During the crisis, our interviewees did not have the time to engage in retrospect sensemaking: often, they were out at the hotspots and it was well after midnight until all refugees were cared for and only a few hours before the next trains would arrive. One of our interviewees $(\mathrm{L})$, a senior official within the City of Vienna, emphasized the importance of action, arguing that "the law of action [das Gesetz des Handelns] is the strongest force" as it constitutes the "normative power of the factual". But how to act, how to decide in the crisis? One interviewee (A) articulated this as the critical question during the crisis: "how quickly can sustainable decisions be made?" To illustrate the significance of the speed of decision making: the records of one of the crisis management centers, the SanStab of the City of Vienna, accounted for 520 decisions that were made during the crisis - each day $(\mathrm{N}) \cdot{ }^{11}$ One of our interviewees described this fast management style as Blitz-Management (E). Decisions were made without much of a pre-decision planning or preparation phase because there was little time and information for such an approach (E). Situations of emergency necessitated rapid decision making en masse and equally rapid action. For instance, a typical decision situation was that 1,000 refugees could not be transported on today, which meant they had to stay overnight. The challenge was to find temporary accommodation, to organize transport, food, etc. (E). Our interviewee spoke of a rapid "switching" towards a tremendously fast management modus in which decision, action, and reflection were short-circuited. Similarly, another senior manager suggested that speed, immersion, and switching resulted in an alternative "model" of decision-making - a model, so s/he added, "that worked really well" (C).

\section{Creating agility through emergence and decentralization}

For the "new model" to emerge, the old established way of doing things had to give way. The story of how the police acted during the crisis is a good illustration of how space for new practices, priorities and

\footnotetext{
11 This number was provided by the SanStab of the City of Vienna and is based on the protocols that register every decision taken in the crisis-management meetings.
} 
partners emerged. In our conversation, a senior police officer (M) bluntly confessed that as thousands of refugees poured into the hot spots the police was not in control of the situation any longer. In theory, police would have had to check IDs of refugees and since most of them were not legally in the country, they would have had to be detained and an application for asylum would have had to be filed. Given the numbers this was de facto impossible $(\mathrm{M} ; \mathrm{O})$.

Without any official direction from the ministry, the local officer $(M)$ decided to focus on crime prevention and safety and not act any longer on breaches of administrative law. In order to cope with the crisis, s/he started "to look for allies" and for "new priorities that were shifting from day to day" (M). In other words, the "legal vacuum" (M) provided the space for experimentation. For instance, the officer stated that prior to the crisis it would have been unheard of that the police would invite a non-certified civilian translator to mediate an official act (Amtshandlung). In the midst of the crisis and the ensuing vacuum, the police was grateful for volunteers to translate or take on other duties, such as escorting refugees to their temporary shelter. As the police officer mused $(M)$, it was much more effective when volunteers did so, as many refugees perceived police in uniform intimidating.

Looking for allies implied a distribution of decision-making laterally to partners previously unknown. This decentralization was paramount for maintaining speed and overall agility. All our interviewees stressed that waiting for a decision from a hierarchically superior unit was usually not an option because solutions needed to be found on the spot. For instance, one pressing issue was that there were many children amongst the refugees. In response, at Westbabnhof, a group of volunteers decided ad hoc to offer a temporary child care facility. In a corner of the train station they organized a play area. Whilst initially skeptical, $O ̈ B B$ came to agree that it was better to have a designated play area than having kids playing uncontrolled in and around the train station (or worse: on the train tracks). The initiative grew and through the mediation of the Caritas a local child care organization got involved. The city administration cleared a public parking deck next to the train station, which provided the space for the "family center". The police and childcare stories are symptomatic for "how things emerged" (A): it was a "process in constant flux" that was stabilized through "ad hoc structures" (A). One interviewee (M) described the emerging order (somehow paradoxically) as "shifting, unstructured, non-hierarchical command structure" in which "issues" and "themes" (and not appropriateness or consequentialist analysis) determined who was playing which role. M described leading and decision-making as situated, collaborative activity.

The analytical point of our story: the breaking down of "business as usual" opened up a legal and institutional vacuum in which alternative ways of doing things could emerge, in which experimentation was possible and in which agility was generated. 


\section{Directionality through bierarchization and countenance}

Decentralized and emerging decision-making are prone to lack coherence and direction; this begs the question: how did the decisions in the collective of actors cohere? What structured their intentionality? Our interviewees observed a process of hierarchization that structured especially the civic grassroot actor Train of Hope, making it more predictable and its contributions cumulative. Train of Hope could draw on the support of some 300,000 citizens that followed it through social media. It was a significant actor throughout the crisis as it managed operations at Hauptbahnhof. Despite its grassroot beginnings, it developed into a quite "autocratic" (F) organization. One of our interviewees (E) described it not without irony as "nasty command-and-control system that could not be any more militaristic" and added that s/he would get into big trouble if s/he adopted this style in his/her own (hierarchical) organization. In fact, one of the leaders of Train of Hope $(\mathrm{H})$ described his/her role as that of "structuring and organizing" resources and energy. For instance, at the beginning, the "front desk", which was the first point of contact for arriving refugees, was chaotic: "We took it over and built in traditional, hierarchical structures". From then on, one person who was under instruction to buy only cheaper group tickets and only to Munich bought train tickets. There was a list of names of refugees and contact numbers through which ticketing was organized. Once on the train, refugee groups were "coded" with a Twitter address so that other Train of Hope volunteers along the route and especially in Munich (the next hotspot) would know who and how many people to expect $(\mathrm{H})$. This coding allowed to find refugees that got lost (indeed, once a group of 12 refugees had to change trains and boarded the wrong train; they were found a few days later and were put back on the right track, literally). To the outside world, Train of Hope "played hierarchy" (H; R; T) so to be more tangible, more reliable for their vis-à-vis. Train of Hope realized that its "lease of life" (Lebensader) depended on being reliable. As our interviewee stressed, s/he and the organization had to "feel their way towards classical hierarchical structures" $(\mathrm{H})$ to mirror other actors externally and to become more efficient internally. Other members of Train of Hope (R; T; Q) used the same vocabulary to describe how the civil-society start-up morphed into an effective organization. At its height, Train of Hope consisted of twelve "departments", each equipped with a head and a small leadership team, protocols, and rules for interaction between departments and third parties, and clear priorities for action (Q; T). All this had to be accomplished although individuals making decisions within Train of Hope did not share previous experiences, nor did they know other actors in the collective. This process of hierarchization made coordination with other organizations easier; Train of Hope and other established actors came closer as they emulated each other's structures, with mediators (such as FSW or ASB) acting as interfaces. On the other side, actors used to hierarchical structures (such as the police or the city administration) loosened up during the crisis and became flatter, which complemented the hierarchization of civil-society actors. This process towards equivalence of structures ensured coherence of the many decisions made whilst retaining collective agility.

There was another, equally important structuring mechanism (especially on the side of established bureaucratic organizations) that made emergent, collaborative forms of decision-making more coherent: 
countenance (Haltung). The already quoted senior official (L) stressed the importance of the moral stance that was articulated at the top, by the mayor, the CEO of $O B B B$, and other leaders. The moral stance was expressed in the two widely shared goals - treating refugees humanely and ensuring order. It was this moral stance, or countenance, that suggested an attitude and direction for people in their decision making (I). The moral stance from the top was an important structuring element of decision-making during the crisis. As mentioned, organizational actors took on risks and responsibilities beyond their legal mandates. This created anxieties: who would cover bureaucratic or civilian decision-makers in case something went wrong? Many of our interviewees reflected on the importance of backing or Rückendeckung. One interviewee reflected on his/her leadership during the crisis as providing such support: "What is leadership? In truth it is about taking responsibility for risk. If you do not take risks, you do not lead" (C). Another senior manager (E) reflected on countenance as boundary condition for decentralized, agile decision making. S/he thought about his/her power not as power to command and control, rather, for $\mathrm{him} /$ her power resided in the obligation to shoulder the responsibility for actions of those reporting to him/her. For our interviewee such decentralized, agile decision making was possible because of the moral stance at the top - the commitment to doing the "right thing" with the means of existing rules, and if necessary, without, perhaps even against them.

It was interesting to see how countenance was instilled into the collective. Symbolic communication through interviews or speeches conveyed the moral stance of those in leadership positions. During an early crisis meeting a welcome poster was designed ad hoc and used as communication tool to welcome the refugees; this poster was reproduced in social media across the world and quickly became a manifestation of countenance (C; E). But countenance was not only about big statements and colorful posters. For decision-makers it was equally about small messages. For instance, countenance was infused into decision-making processes through communication technology such as text messaging. This new, speedy form of communication between decision-makers and actors on the ground brought what the German Halt in Haltung denotes to decisions: i.e., guidance and stability. As one manager (C) said, "I always had capacity to act in meetings, I always had a decision" as C did not need to go back to his/her political masters after the meeting but could get-go on the spot. If the equivalence of structures ensured the intentionality of the collective, countenance was the moral scaffolding that enabled actors to deal with anxieties arising from transcending institutional frameworks and making decisions in a legal vacuum.

\section{DISCUSSION AND CONCLUSION}

\section{In search for an alternative framing: Clausewitz' logic of tact}

In this paper we seek to answer the question how decision-makers orchestrate collective action during crisis. A Ricœur-inspired reading of the crisis highlighted that experience lost its relevancy as repertoire of learnt responses; and expectations faded into an unpredictable future. The crisis was foremost a crisis of temporality, in which neither retro-spection nor pro-spection could inform decision-making sufficiently. Hence, the decision-makers we interviewed lost the ability to calculate their way towards rational 
decisions, nor did they have faith to rely on well-rehearsed scripts and enshrined templates to arrive at what was appropriate action. The refugee crisis represented a loss of orientation, an incision that cut past experiences from future expectations forcing our decision-makers to act without the comfort of rational models or social scripts. There was neither an algorithm enabling calculation nor a protocol allowing orientation. Put theoretically, March's two logics of decision-making and Weick's theory of sensemaking provided a somehow incomplete conceptual tool to make sense of our findings.

So how do decisions happen during crisis? Our analysis did not only problematize the established logics, it also revealed four elements that enabled decision-making: two more cognitive-inflected elements (sensing of the situation as experiential, bodily activity; and sensing as distributed, collective accomplishment), and two action-oriented elements (creating agility and ensuring directionality). Importantly, our study highlighted the rapid interplay between these elements as critical for decision-making.

This rapid interplay lead us to Clausewitz who reflected on how cognition and action relate to each other so to sustain the capacity to make decisions in the midst of the fog of war. ${ }^{12}$ Clausewitz invites theorization of our findings through placing tact at the heart of the decision-action nexus during crisis. In his posthumously published oeuvre $O n W a r(1832 / 2005)$ Clausewitz argued that in the midst of war - and by analogy, other crisis situations - there can be no "algebra of action" (1832/2005: 19) nor a general "law" (1832/2005: 138) that can inform decision-making:

"War is the province of uncertainty: three-fourths of those things upon which action in war must be calculated, are hidden in the fog of more or less great uncertainty." (Clausewitz, 1832/2005:

$65)^{13}$

This is Clausewitz' challenge: whilst it is impossible to analyze let alone predict events, there is the necessity to sustain the capacity to decide and act. The concept of tact captures this capacity, as the previous quote continues:

\footnotetext{
${ }^{12}$ As military theorist, Clausewitz was interested in the epistemological regime of warfare. Clausewitz developed his thoughts in response to the Napoleonic Wars, which brought about a complete change in the conduct of war (Engberg-Pedersen, 2015). Continuous movement and a constantly changing theater of war resulted in a hitherto unknown dynamic. Tolstoy's description of the battle of Austerlitz provides an apt illustration: even the very fact of war itself - how and where - even if? - a battle was taking place, is disputed in Tolstoy's narrative. In this sense, warfare can be read as Clausewitz's chiffre for complex situations that evade rational analysis. In fact, Clausewitz struggled to define war to a point where he argued that there is no clear distinction between war and non-war. This makes war an interesting ontological category that transcends military studies and the battlefield: what we know about war is that we cannot comprehend it; the only "fact" is the fog that shrouds our senses and a complexity that perplexes our minds. It is not the (rather problematic) analogy between warfare and society that make Clausewitz an important intellectual resource; rather, what makes engagement with Clausewitz fruitful is the fact that he is one of the first and foremost thinkers who is concerned with an alternative modus operandi ('tact') in situations where neither rational analysis nor reliance on traditional scripts suffice to uphold our capacity to move from thought to action.

${ }^{13}$ Translations of Clausewitz by the authors who consulted various English editions of On war and amended them where necessary.
} 
"Here, then, above all a fine and penetrating mind is called for, to feel out [berausfïblen] the truth by the tact of its judgment."

For Clausewitz, it is tact that allows "feeling out of the truth" in the midst of the fog. Hence, tact represents an alternative epistemic model for decision-making in a world in which rational analysis of consequences and institutionalized rules of appropriateness both fail to provide guidance. This alternative epistemic model places tact as the quickest link between cognition and action at the core of decisionmaking: "As the ability to transform complex information into action, tact is the central skill in any situation where the conditions are similar to the state of war. It is, [Clausewitz] writes, the "soul of action"" (Engberg-Pedersen, 2015: 81). In this sense tact is the "mediating link between the mind and the world and is seen as particularly useful in situations where the world is in constant flux" (EngbergPedersen, 2015: 70). Tact implies "feeling out" of patterns that structure the situation; this understanding is a sensing, a form of bodily perception that is at the same time a reflection of the situation and abstraction from its specificities in order to arrive at a decision.

\section{Modeling the logic of tact}

Clausewitz distinguished between two specific moments that constitute tact and that reflect our findings: coup d'ail and courage d'esprit. With coup d'ail he describes the ability to see things with the "intuitive eye" at a glance: "the rapid discovery of a truth, which to the ordinary mind is either not visible at all or only becomes so after long examination and reflection" (1832/2005: 67). The coup d'xil is working "almost subconsciously" (208), and, in contrast to rational analysis, tact requires "phantasy" to draw an "inner map" of the situation (81). The logic of tact "consists unquestionably more or less in some intuitive comparison of things and relations" as Clausewitz argues (298), including scanning and prioritizing. The decision-maker is "in touch" with what goes on, emphasizing the fact that tact is both sensual and intellectual simultaneously. ${ }^{14}$ Moreover, tact has to be exercised quickly, requiring what Clausewitz called "presence of mind" (69). The mind is not caught up in calculations, however, but in "guessing": "It is, at all times, only conjecture or guesses at truth which we have to act upon" (78). In short, the coup d'cil represents a specific epistemic regime based on impressions (not representations), on Fingerspitzengefiubl (not computing power) and distributed perception (not centralized surveillance); all contributing to the "feeling out" of a situation - an embodied, distributed and tactile form of sensemaking that we found in our data. In this sense, our narrative contrasts more orderly attempts to build "system architectures" for shared situational awareness and common operational pictures (Wolbers \& Boersma, 2013) and echoes more distributed, embodied forms of collective sensemaking (see Kendra \& Wachtendorf, 2006).

With the second element of tact, courage d'esprit, Clausewitz captures those qualities that allow the decisionmaker to follow through on what is revealed through the coup d'ail:

\footnotetext{
${ }^{14}$ The conflicting etymology of tact illustrates the point (Engberg-Pedersen, forthcoming): tact from the Greek verb tássein meaning "to organize", "to put into order"; and from the Latin tangere, meaning "sense of touch".
} 
"Now, if it is to get safely through this perpetual conflict with the unexpected, two qualities are indispensable: in the first place an understanding which, even in the midst of this intense obscurity, is not without some traces of inner light, which lead to the truth, and then the courage to follow this faint light. The first is figuratively expressed by the French phrase coup d'cil. The other is determination [courage d'esprit]." (Clausewitz, 1832/2005: 66).

Courage d'esprit denotes agility and fast (blits) decision-making; it captures the decisiveness and determination of action in crisis situations. For Clausewitz agility is inherently related to tact: a swift, yet measured response, directed without following a preconceived plan, rapidly switching between thinking and acting. The logic of tact helps to understand how in our case decision-makers oriented their actions towards each other during the crisis; how through the logic of tact they explored and exploited the "legal vacuum" in which they took the law of action (das Gesetz des Handelns) into their own hands. What we encounter is a dynamic model in which counteracting forces contribute to effective decision-making under duress: decentralization and emergence on the one hand, and hierarchization and countenance on the other hand worked as centrifugal and centripetal forces that keep each other on track not unlike a roller coaster: the former created agility, while the latter provided direction and ensured traction of energies set free. Together with the coup d'ail (the sensing of the situation with its experiential and distributed characteristics) the courage d'esprit (with its focus on agility and directionality) describes the logic of tact as alternative model of decision-making (see summary figure below for a schematic representation).

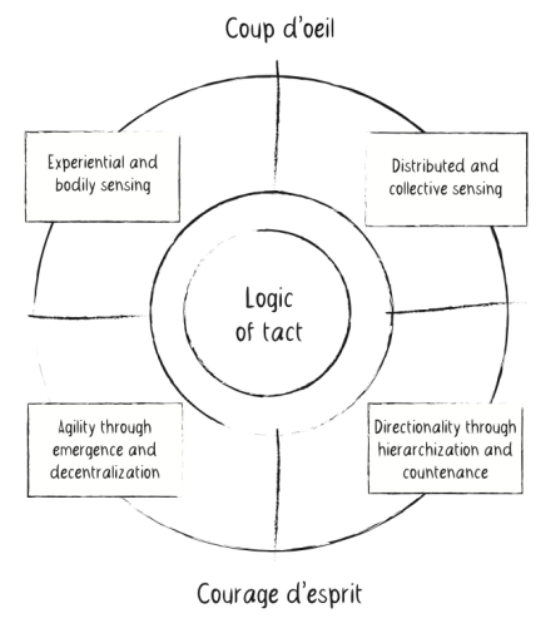

Figure 3: The logic of tact and its elements

Importantly, the outlined elements of the logic of tact do not work sequentially; rather, the logic of tact is a dynamic model in which the elements represent (centrifugal, centripetal) forces that balance each other: the model does not allow predicting the outcome, but offers a diagram of forces invested in the struggle. 
In sum, with Clausewitz we can theorize our findings and define the logic of tact as alternative modus operandi of decision makers during crisis. In order to fully develop this concept of tact, we will define the nature of tact and discuss its relationships with decision-making and sensemaking.

\section{Defining tact}

Tact surfaced in the late $18^{\text {th }}$ century as Western society became increasingly fragmented and complex (Engberg-Pedersen, 2015). Enshrined cognitive schemata and established categorizations lost reliability and relevance for structuring and decoding social encounters. Tact emerged in response to this new complexity, as the literature historian Russell (2012: 180) suggested:

“The OED [Oxford English Dictionary] credits Stewart with the first use of 'tact' to mean a practice of sociability in 1793. He observed that the French found a need for tact - for a person's capacity to 'feel his way' among others - in the context of the immense upheaval of the French revolution and the ensuing terror. Stewart's use of tact implies that modern social changes, if they are not to become violent, require a less certain and knowing way of handling others."

Following this definition tact is the modus of approaching an unknown situation and the ability to orient oneself in it swiftly. As Russell (2013: 123) elaborated, tact

“is a response to new social conditions, of dubiety about one's assigned place in any prescribed order, and a wider uncertainty about orders themselves; a situation in which, as Arnold put it in his 1863 essay on Marcus Aurelius, people must 'walk by sight, not by faith, but yet have no open vision."”15

Tact, Russell (2012: 180) argued, "resists the codification of social laws and the pinning of individuals to fixed meanings; it is an ethic of the ad hoc, continually rereading and rewriting the social". Tact is orientation without indexing and categorizing - the ability to switch quickly between knowing and doing, between cognition and action in order to arrive at a meaningful, measured response to a complex situation. Whilst tact has taken on several meanings (tact in music, tact as in tactic, etc.), we use it in the sense of "walking by sight, not by faith, but yet have no open vision" as Russell emphasized, leading us to a provisional definition of tact as the ability to make decisions and take action in situations where traditional social scripts and cognitive schemata fall short of providing orientation and where meaningful action requires acting situationally in concert with other decision-makers.

\section{Logic of tact and decision-making theory}

\footnotetext{
${ }^{15}$ Russel refers to the English writer Matthew Arnold (1822-1888) and his essay Marcus Aurelius, first published in The Victoria Magazine, II, 1-9, November, 1863. See https://ebooks.adelaide.edu.au/a/arnold/matthew/marcusaurelius/
} 
What are the implications of our analysis for ongoing conversation in research? The first more general learning relates to March's two logics of decision-making. As our narrative illustrated, our decision-makers followed neither the logic of appropriateness nor the logic of consequences: rather, actors transcended traditional roles and established categorizations as new actors arrived on the stage whilst ambiguity and uncertainty made rational calculation of means and ends a hope perdue. Alternatively, we suggest the logic of tact (or what Ricœur alludes to as "engagement") as alternative modus operandi that guides decisionmaking in the fog of crisis. With Engberg-Pedersen (forthcoming) we argue that tact is

"the cognitive faculty invoked to make sense of our senses. Establishing an aesthetic order, the sense of tact extends its ghostly hands to feel out the truth that does not have the universality or regularity of a law, but that nevertheless enables actions that are apt and meaningful."

Translated into our context, the logic of tact describes how decision-making orchestrated collective action in a situation of crisis. The other two logics rely (metaphorically speaking) on the decision-maker's calculator or the decision-maker's memory; the logic of tact emerges when there is no calculation and no script to remember; rather, tact circumscribes a careful Sichberantasten to a situation that does not follow (as Engberg-Pedersen (forthcoming) puts it) a law but that "nevertheless enables actions that are apt and meaningful".

\begin{tabular}{|l|l|l|l|}
\hline & Logic of appropriateness & Logic of consequences & Logic of tact \\
\hline Epistemic regime & $\begin{array}{l}\text { Decoding situation and } \\
\text { subsumption under rule } \\
\text { (identity) }\end{array}$ & $\begin{array}{l}\text { Extrapolating future } \\
\text { effects of decision (cost } \\
\text { benefit analysis) }\end{array}$ & $\begin{array}{l}\text { Emergent, "walking by sight } \\
\text { without faith and open } \\
\text { vision" }\end{array}$ \\
\hline Ontological condition & $\begin{array}{l}\text { Reliable past, stable roles, } \\
\text { institutionalized identities }\end{array}$ & $\begin{array}{l}\text { Knowable future, } \\
\text { computing capacity of } \\
\text { decision maker, stable } \\
\text { preferences }\end{array}$ & $\begin{array}{l}\text { Fog of events: uncertainty in } \\
\text { regards to past and future, } \\
\text { neither algorithm nor } \\
\text { protocols }\end{array}$ \\
\hline Temporal structure & Past & Future & $\begin{array}{l}\text { Present } \\
\text { making }\end{array}$ \\
\hline $\begin{array}{l}\text { Critical skills of decision } \\
\text { maker }\end{array}$ & $\begin{array}{l}\text { Orientation at social script; } \\
\text { habitual }\end{array}$ & $\begin{array}{l}\text { Orientation at rational } \\
\text { procedure; calculative }\end{array}$ & $\begin{array}{l}\text { Orientation at event; feeling } \\
\text { out of situation }\end{array}$ \\
& $\begin{array}{l}\text { of others, response based } \\
\text { on institutionalized identity } \\
\text { and shared repertoire of } \\
\text { action }\end{array}$ & $\begin{array}{l}\text { courses of action, } \\
\text { predicting outcomes of } \\
\text { decisions }\end{array}$ & $\begin{array}{l}\text { Engaging in coup } d \text { coil and } \\
\text { courage d'esprit in order to } \\
\text { sustain capacity to act under } \\
\text { duress }\end{array}$ \\
\hline
\end{tabular}

Table 1: Summary table: three complementary logics of decision-making

Tact emerged as ability to navigate the increasingly complex social world of the late $18^{\text {th }}$ century in which social codes and categorizations broke down. With due reference to its literary origins, we defined tact as 
the art of "walking by sight, not faith nor open vision" (see Russell's quote above). We can extend this conceptualization by interpreting faith as appropriateness and open vision as possibility of calculating a knowable future. Therein lies the first contribution of our study: to offer a better understanding of how managers make decisions under the condition of bounded rationality and the simultaneous transgression of their institutional identity in situations of crisis. In other words, the logic of tact enables managers to sustain their capacity to make decisions and act collectively even when there is no shared set of rules to fall back on nor a calculable future to draw upon.

Introducing the logic of tact raises the question of the relationship between tact, appropriateness, and consequentialism. As argued, the logic of tact does not replace but complements March's logics in situations where they are insufficient to structure the relationship between thought and action. In fact, our endeavor still follows March in spirit, if not in concept: March never claimed that consequentialism and appropriateness exhaust possible decision-making logics; rather, he depicted - but never systematically developed - explorative logics (e.g., March's writing on foolishness, e.g., 1971; 2006) which, in a certain way, we develop further with the notion of tact. We argue that the logic of tact has its own distinct temporality. Tact is a Sichherantasten to other actors to develop rapport; tact, in this sense, is a mode of exploring unknown social spaces in which one finds oneself. Tact is also a Sichberantasten to the situation to discover interesting preferences and alternative lines of action. Here, tact is a mode of exploring possible future preferences, whilst simultaneously gauging support for alternatives. This argument is in line with March who argued that "the study of decision making is, in many ways, the study of search and attention" (1994: 23). Where we departed in our analysis is the kind of activity that constitutes this search: decisionmaking is neither an instrumental nor an interpretative activity as March suggested (1994: ix), but, following the logic of tact, a heuristic activity - neither solving a calculus nor relying on shared identity, it is about producing alternatives, a form of "possibilism" (Hirschman, 1971) exercised under duress.

A further qualification concerns the use of logic in logic of tact. What we describe is not a higher-level decision-making logic than the other two; nor is it a logic in the strict, formal sense of the word. Indeed, tact is a modus operandi that our decisions-makers engaged during crisis. The logic of tact captures the structural interplay of cognition and action in decision-making under duress. In this respect, tact resembles something that is closer to the meaning of the Greek word logos rather than the more narrow logic. Similarly, the logic of appropriateness is not a formal logic, but foregrounds the structuring work performed by identity and shared history. Equally, the logic of tact refers to the structuring of decisionmaking under duress.

\section{Bridging decision-making and sensemaking: the logic of tact as missing conceptual link}

A second learning from our case concerns the relation between tact as decision-making logic and sensemaking. In describing the logic of tact as an alternative decision-making logic that relies (next to courage d'esprit) on distributed sensing and embodied cognition, our analysis of decision-making drifted 
towards Weickian sensemaking. Weick's theory represents a critique of decision-making based on the logic of consequences. For Weick it is strategic rationality that informs decision-making and depicts it as rational-choice problem. With the logic of tact, we share this critique whilst we propose a more nuanced logic of decision-making, which builds upon key insights offered by sensemaking. Sensemaking's "contextual rationality" informs the logic of tact in several respects, including through its critique of the supposed primacy of thought over action, its emphasis on decision-making as embodied action (vs. abstract cognitive models), and through sensemaking's distributed nature (vs. the focus on the decisionmaker's mind).

Besides these important commonalities, there are some critical differences between sensemaking and tact. Identity-based cues that are at the heart of sensemaking (Weick, 1995; see Kendra \& Wachtendorf, 2006) echo what March analyzed as logic of appropriateness. Both rely on a shared sense of identity as coordination mechanism; but it is exactly the lack of such a shared sense of identity that we encountered in our case and theorized with the concept of tact: sensemaking (and the logic of appropriateness) assume a shared social stratum, a shared repertoire of social cues that make actors intelligible to each other. But our story is one in which actors could not rely on such a repertoire, and even those actors who did know each other had to do things that estranged them from their usual self (e.g., acting "unbureaucratically" as a bureaucracy). In these situations, we found the logic of tact to guide decision-making. Theorizing our findings, we suggest that tact is neither located in individual cognition nor to be found in historically and socially shaped repertoires of appropriateness; rather, tact is the capability to explore relations between the individual mind and social meaning systems in which the former is embedded; neither inside nor outside, neither following an atomistic cogito's preference nor a social script's norms, tact captures how mind and world relate to each other in situations where one "walks by sight without faith and open vision" (see Russell, 2013).

A second point of critique is sensemaking's emphasis on retrospection. Sensemaking "involves the ongoing retrospective development of plausible images that rationalize what people are doing." (Weick et al., 2005: 409). Here, sensemaking serves as "reminder that action is always just a tiny bit ahead of cognition, meaning that we act our way into belated understanding" (Weick et al., 2005: 419). It is about providing plausible interpretations of events after they occurred. Whereas rational choice would postulate that thinking precedes action, sensemaking turns the arrow around arguing that action is "ahead of cognition". In the light of our case, the focus on retrospection and the primacy of action over thinking is problematic, however: Sure, sometimes "cognition lies in the path of action" (Weick, 1988: 307) - but only sometimes. And sure, sometimes decision-making happens after the fact as a form of postrationalization - but not every decision is a post-rationalization. Instead, and consistent with our findings, tact suggests that the relationship between sensemaking and decision-making is neither one of mutual exclusion (sensemaking as alternative to decision-making, as sensemaking literature seems to suggest); nor is it a sequential one where sensemaking precedes decision-making, as Maitlis (2005: 21; quoting Weick) 
argued: "Sensemaking thus both precedes decision making and follows it: sensemaking provides the 'clear questions and clear answers' (Weick, 1993: 636) that feed decision making, and decision making often stimulates the surprises and confusion that create occasions for sensemaking." Sensemaking is portrayed as the locus of the social, the interpretative, and the reflexive; while decision-making remains black-boxed as moment of rational choice. The logic of tact shows the dynamic interplay between the two: neither is cognition abead of action, nor is action abead of cognition; rather, tact explicates the rapid switching and mutual constitution of thought and action, and how this interplay between coup d'ceil and courage d'esprit orchestrates decision-making during crisis. Therein lies the second contribution of our paper.

\section{Implications for future research}

Our paper has the potential to inspire research in several related fields of inquiry. First, the logic of tact contributes to attempts at saving decision-making from rational choice theorists and their critics. Adding to work on analogical reasoning (Gavetti, Levinthal \& Rivkin, 2005), improvisation (Kamoche \& Cunha, 2003), and decision heuristics (Bingham \& Eisenhardt, 2011; Gigerenzer \& Gaissmaier, 2011), we propose that tact zooms in on how decisions are made in conditions of crisis. With the concept of tact we extend decision-making theory and suggest a conceptual tool that allows analyzing modalities of cognition (coup d'ceil) and action (courage d'esprit) as well as their dynamic interplay.

Second, the logic of tact complements the sensemaking research agenda. For instance, Weick et al. (2005) called for future research on sensemaking and its relation to emotion, power, and institutional theory; Maitlis and Christianson (2014) added further linkages to change, learning, creativity, and innovation. Our study proposes rethinking the fundamental relationship between sensemaking and decision-making, and in so doing it questions taken-for-granted distinctions between retrospection and prospection and the relation between contextual and strategic rationalities. Tact provides the conceptual linkage that enables such dialogue.

Third, our paper calls for future research into how decision makers cope with logic multiplicity (Vurro, Dacin \& Perrini, 2010; Thornton, Ocasio \& Lounsbury, 2012; Meyer \& Höllerer, 2016) when addressing grand challenges in society (Besharov \& Smith, 2014; Ferraro, Etzion \& Gehman, 2015). Yet, the logic of tact is not another type of institutional logic tied to a particular institutional domain, nor a specific strategy that actors employ; rather it describes a modus operandi that enables a collective of decision makers to deal with multiple logics.

Finally, our study invites new problematizations in the crisis management literature: recently, insightful studies have explored how multiple actors collaborate and develop emergent crisis response strategies and learn (Wolbers \& Boersma, 2013; Antonacopoulou \& Sheaffer, 2014), collaborate (Beck \& Plowman, 2014; Oscarsson \& Danielsson, 2018), and make sense (Kendra \& Wachtendorf, 2006) during crisis. Our investigation adds to this research by focusing on the logic of decision-making during crisis and introduces tact as conceptual tool to understand how cognition and action relate to each other. This contribution is 
based on a specific understanding of the phenomenon of the crisis which we defined with Ricœur as moment of decision. Such a focus on crisis and decision could orchestrate a research agenda in which currently several notions (including disaster, risk, and crisis; van der Vegt et al., 2015) compete for researchers and policy makers' attention. 


\section{LITERATURE}

Abolafia, M. Y. (2010). Narrative construction as sensemaking: How a central bank thinks. Organization Studies, 31, 349-367.

Alvesson, M., \& Kärreman, D. (2007). Constructing mystery: Empirical matters in theory development. Academy of Management Review, 32, 1265-1281.

Antonacopoulou, E. P., \& Sheaffer, Z. (2014). Learning in crisis: Rethinking the relationship between organizational learning and crisis management. Journal of Management Inquiry, 23, 5-21.

Bechky, B. A., \& Okhuysen, G. A. (2011). Expecting the unexpected? How SWAT officers and film crews handle surprises. Academy of Management Journal, 54, 239-261.

Beck, T. E., \& Plowman, D. A. (2014). Temporary, emergent interorganizational collaboration in unexpected circumstances: A study of the Columbia space shuttle response effort. Organization Science, 25, 1234-1252.

Besharov, M. L., \& Smith, W. K. (2014). Institutional antecedents of partnering for social change: How institutional logics shape cross-sector social partnerships. Journal of Business Ethics, 94, 39-53.

Bingham, C. B., \& Eisenhardt, K. M. (2011). Rational heuristics: The "simple rules" that strategists learn from process experience. Strategic Management Journal, 32, 1437-1464.

Boin, A., Ekengren, M., \& Rhinard, M. (2014). Making sense of sense-making: The EU's role in collecting, analysing, and disseminating information in times of crisis. Research Report, The Swedish National Defence College.

Boin, A., Rhinard, M., \& Ekengren, M. (2014). Managing transboundary crises: the emergence of European Union capacity. Journal of Contingencies and Crisis Management, 22, 131-142.

Clausewitz, C. von (1832/2005). Vom Kriege. Stuttgart: Reclam.

Cunliffe, A., \& Coupland, C. (2012). From hero to villain to hero: Making experience sensible through embodied narrative sensemaking. Human Relations, 65, 63-88.

Danner-Schröder, A., \& Geiger, D. (2016). Unravelling the motor of patterning work: Toward an understanding of the microlevel dynamics of standardization and flexibility. Organization Science, 27, 633658.

Dutton, J. E. (1986). The processing of crisis and non-crisis strategic issues. Journal of Management Studies, 23, 501-517. 
Engberg-Pedersen, A. (2015). Empire of chance: The Napoleonic war and the disorder of things. Cambridge: Harvard University Press.

Engberg-Pedersen, A. (forthcoming). The sense of tact: Hoffmann, Maelzel, and mechanical music. Working paper.

Entwistle, T. (2011). For appropriateness or consequences? Explaining organizational change in English local government. Public Administration, 89, 661-680.

Ferraro, F., Etzion, D., \& Gehman, J. (2015). Tackling grand challenges pragmatically: Robust action revisited. Organization Studies, 36, 363-390.

Gavetti, G., Levinthal, D. A., \& Rivkin, J. W. (2005). Strategy making in novel and complex worlds: The power of analogy. Strategic Management Journal, 26, 691-712.

Gephart, R. P., Jr. (1984). Making sense of organizationally based environmental disasters. Journal of Management, 10, 205-225.

Gephart, R. P., Jr. (2007). Crisis sensemaking and the public inquiry. In C. M. Pearson, C. Roux-Dufort \& J. A. Clair (Eds.), International handbook of organizational crisis management (pp. 123-160). Thousand Oaks: Sage.

Gigerenzer, G., \& Gaissmaier, W. (2011). Heuristic decision-making. Annual Review of Psychology, 62, 451482.

Gioia, D. A., Corley, K. G., \& Hamilton, A. L. (2013). Seeking qualitative rigor in inductive research: Notes on the Gioia methodology. Organizational Research Methods, 16, 15-31.

Goldmann, K. (2005). Appropriateness and Consequences: The Logic of Neo-Institutionalism. Governance, $18,35-52$.

Hermann, C. F. (1963). Some consequences of crisis which limit the viability of organization. Administrative Science Quarterly, 8, 61-82.

Hirschman, A. O. (1971). Bias for hope: Essays on development and Latin America. New Haven: Yale University Press.

James, E. H., \& Wooten, L. P. (2010). Leading under pressure: From surviving to thriving before, during, and after a crisis. New York: Routledge Press.

James, E. H., Wooten, L. P., \& Dushek, K. (2011). Crisis management: Informing a new leadership research agenda. Academy of Management Annals, 5, 455-493. 
Kamoche, K., \& Cunha, J. V. D. (2003). Towards a theory of organizational improvisation: Looking beyond the jazz metaphor. Journal of Management Studies, 40, 2023-2051.

Kendra, J., \& Wachtendorf, T. (2006). The waterborne evacuation of lower Manhattan on September 11: A case of distributed sensemaking. Preliminary paper, University of Delaware.

Kopelman, S., Hardin, A. E., Myers, C. G., \& Tost, L. P. (2016). Cooperation in multicultural negotiations: How the cultures of people with low and high power interact. Journal of Applied Psychology, 101, 721-730.

Kornberger, M., Leixnering, S., Meyer, R.E., \& Höllerer, M. (forthcoming). Rethinking the Sharing Economy: The Nature and Organization of Sharing in the 2015 Refugee Crisis. Academy of Management Discoveries, https://doi.org/10.5465/amd.2016.0138

Lueger, M., Sandner, K., Meyer, R., \& Hammerschmid, G. (2005). Contextualizing influence activities: An objective hermeneutical approach. Organization Studies, 26, 1145-1168.

MacDonald, L. D., \& Richardson, A. J. (2004). Identity, appropriateness and the construction of regulatory space: The formation of the public accountant's council of Ontario. Accounting, Organizations and Society, 29, 489-524.

Maitlis, S. (2005). The social processes of organizational sensemaking. Academy of Management Journal, 48, $21-49$.

Maitlis, S., \& Christianson, M. (2014). Sensemaking in organizations: Taking stock and moving forward. Academy of Management Annals, 8, 57-125.

March, J. G. (1971). The technology of foolishness. Civilokonomen, 18(4), 4-12.

March, J. G. (1978). Bounded rationality, ambiguity, and the engineering of choice. The Bell Journal of Economics, 9, 587-608.

March, J. G. (1982). Theories of choice and making decisions. Society, 20, 29-39.

March, J. G. (1994). A primer on decision making: How decisions happen. Free Press: New York.

March, J. G. (2006). Rationality, foolishness, and adaptive intelligence. Strategic Management Journal, 27, 201214.

March, J. G., \& Olsen, J. P. (2015). The logic of appropriateness. In R. E. Goodin (Ed.), The Oxford handbook of political science (pp. 478-497). Oxford: Oxford University Press. 
Meyer, R. E. \& Höllerer, M. A. (2016). Laying a smoke screen: Ambiguity and neutralization as strategic responses to intra-institutional complexity. Strategic Organization, 14, 373-406.

McCarter, M. W., Budescu, D. V., \& Scheffran, J. (2011). The give-or-take-some dilemma: An empirical investigation of a hybrid social dilemma. Organizational Behavior and Human Decision Processes, 116, 83-95.

Mills, C. W. (1959). The sociological imagination. New York: Oxford University Press.

Morin, E. (1993). Towards a crisiology. Industrial and Environmental Crisis Quarterly, 7, 5-23.

Ocasio, W. (1999). Institutionalized action and corporate governance: The reliance on rules of CEO succession. Administrative Science Quarterly, 44, 384-416.

Oscarsson, O., \& Danielsson, E. (2018). Unrecognized crisis management-Normalizing everyday work: The work practice of crisis management in a refugee situation. Journal of Contingencies and Crisis Management, 26(2), 225-236.

Ostrom, E. (2010). Beyond markets and states: Polycentric governance of complex economic systems. Transnational Corporations Review, 20, 1-12.

Pearson, C., \& Clair, J. A. (1998). Reframing crisis management. Academy of Management Review, 23, 59-76.

Perrow, C. (1984). Normal accidents: Living with high risk technologies. New York: Basic Books.

Ricœur, P. (1988). La crise: Un phénomène spécifiquement moderne? Revue de Théologie et de Pbilosophie, $120,1-19$.

Ronge, B. (2015). Das Elend der krisenfokussierten Ökonomiekritik. Zum Verhältnis von Kritik und Krise bei Karl Marx und Adam Smith. In M. G. Festl, F. Grosser \& D. Thomä (Eds.), Über Krise und Kritik (pp. 75-92). Basel: Schwabe AG Verlag.

Roux-Dufort, C., \& Lalonde, C. (2013). Exploring the theoretical foundations of crisis management. Journal of Contingencies and Crisis Management, 21, 1-3.

Russell, D. J. (2012). "Our debt to lamb”: The romantic essay and the emergence of tact. ELH, 79, 179209.

Russell, D. J. (2013). Teaching tact: Matthew Arnold on education. Raritan, 32(3), 109-139.

Ryle, G. (1971). Collected papers. Volume II: Collected essays, 1929-1968. London: Hutchinson.

Schulz, M. (2014). Logic of consequences and logic of appropriateness. In M. Augier \& D. Teece (Eds.), Palgrave encyclopedia of strategic management (pp. 1-6). London: Palgrave Macmillan. 
Scott, J. C. (1998). Seeing like a state: How certain schemes to improve the human condition have failed. New Haven: Yale University Press.

Scott, W. R. (1995). Institutions and organizations. Thousand Oaks: Sage.

Simsa, R. (2017). Leaving emergency management in the refugee crisis to civil society? The case of Austria. Journal of Applied Security Research, 12(1), 78-95.

Stigliani, I., \& Ravasi, D. (2012). Organizing thoughts and connecting brains: Material practices and the transition from individual to group-level prospective sensemaking. Academy of Management Journal, 55, 1232-1259.

Thomä, D., Festl, M. G., \& Grosser, F. (2015). Einstimmung: Vier Etappen der Geschichte von Kritik und Krise. In M. G. Festl, F. Grosser \& D. Thomä (Eds.), Über Krise und Kritik (pp. 11-20). Basel: Schwabe AG Verlag.

Thornton, P. H., Ocasio, W., \& Lounsbury, M. (2012). The institutional logics perspective: A new approach to culture, structure, and process. Oxford: Oxford University Press.

Van der Vegt, G. S., Essens, P., Wahlström, M., \& George, G. (2015). Managing risk and resilience. Academy of Management Journal, 58, 971-980.

Vaughan, D. (1996). The challenger launch decision. Chicago: The University of Chicago Press.

Vurro, C., Dacin, M. T., \& Perrini, F. (2010). Multiple institutional logics in organizations: Explaining their varied nature and implications. Academy of Management Review, 39, 364-381.

Wagnsson, C. (2010). Divided power Europe: Normative divergences among the EU "big three". Journal of European Public Policy, 17, 1089-1105.

Weick, K. E. (1979). The social psychology of organizing. Boston: Addison-Wesley Publishing Company.

Weick, K. E. (1988). Enacted sensemaking in crisis situations. Journal of Management Studies, 25, 305-317.

Weick, K. E. (1993). The collapse of sensemaking in organizations: The Mann Gulch disaster. Administrative science quarterly, 38, 628-652.

Weick, K. E. (1995). Sensemaking in organizations. Thousand Oaks: Sage.

Weick, K. E. (1996). Drop your tools: An allegory for organizational studies. Administrative Science Quarterly, $41,301-313$. 
Weick, K. E. (2010). Reflections on enacted sensemaking in the Bhopal Disaster. Journal of Management Studies, 47, 537-550.

Weick, K. E., Sutcliffe, K. M., \& Obstfeld, D., (2005). Organizing and the process of sensemaking. Organization Science, 16, 409-421.

Wicks, D. (2002). Institutional bases of identity construction and reproduction: The case of underground coal mining. Gender, Work \& Organization, 9, 308-335.

Wilhelm, H., \& Bort, S. (2013). How managers talk about their consumption of popular management concepts: Identity, rules and situations. British Journal of Management, 24, 428-444.

Wolbers, J., \& Boersma, K. (2013). The common operational picture as collective sensemaking. Journal of Contingencies and Crisis Management, 21, 186-199.

\footnotetext{
${ }^{i}$ We would like to thank the editor as well as the four anonymous reviewers for their invaluable feedback; moreover we are indebted to the following friends and colleagues: Anders Engberg-Pedersen, Christof Brandtner, Corinna Frey, David Courpasson, David Russell, Jan Mouritsen, Jeremy Adelman, Jim March, Kristian Kreiner, Marian Gatzweiler, Michael Barrett, Morten Knudsen, Oliver Will and Philippe Riot.
} 